68

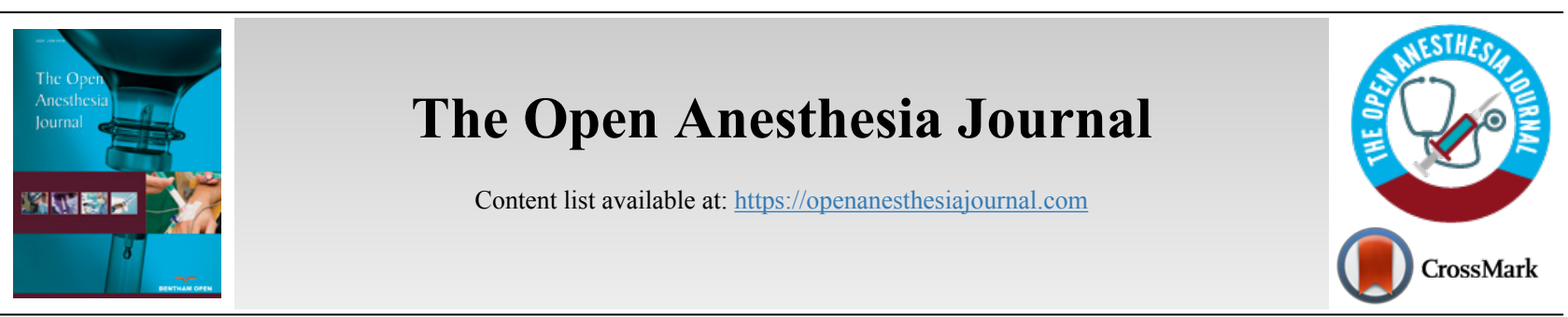

RESEARCH ARTICLE

\title{
Efficacy of Dexmedetomidine Infusion Without Loading Dose as a Potent Hypotensive Agent in Lumbar Fixation Surgery
}

\author{
Assem Adel Moharram ${ }^{1}$ and Raham Hasan Mostafa, ${ }^{1, *}$ \\ ${ }^{1}$ Department of Anesthesia and Intensive Care, Faculty of Medicine, Ain Shams University, Cairo, Egypt.
}

\begin{abstract}
:
Background:

Dexmedetomidine on the basis of the previous literature can be considered a safe agent for controlled hypotension through its central and peripheral sympatholytic action. Its easy administration and absence of fatal side effect make it a near-ideal hypotensive agent. This study was intended to evaluate the efficacy of dexmedetomidine infusion "without loading dose" as an effective hypotensive agent in lumbar fixation surgery.

Methods:

In a double-blind study, a total of 60 patients aged 18-65 years, of both genders, belonging to the American Society of Anesthesiologist (ASA) class I - II scheduled for elective lumbar spine instrumentation were included and divided into: Control group (Group C) who received placebo and Dexmedetomidine group (Group D) who received Intravenous (IV) dexmedetomidine. The patients were compared primarily for intraoperative hemodynamics.

Results:

The study results showed that dexmedetomidine had successfully maintained target mean blood pressure of $65-70 \mathrm{mmHg}$ and only 2 patients out of 30 required rescue therapy (both of propofol and NG). Also, dexmedetomidine had maintained heart rate stability than the control group from the $15^{\text {th }}$ minute after positioning till the end of surgery $(P$-value $<0.001)$. Intraoperative fentanyl consumption was significantly low in Dexmedetomidine group $75 \pm 25.43 \mu \mathrm{g}$ versus $169.64 \pm 34.26 \mu \mathrm{g}$ in Control group $(P$-value $<0.001)$. Finally, more post-operative sedation was noticed during the $1^{\text {st }}$ postoperative hour in dexmedetomidine group when compared to the control group $(P$-value $<0.001)$.

Conclusion:

Dexmedetomidine infusion without loading dose could be an effective and safe agent in achieving controlled hypotension in adults undergoing elective lumbar spine instrumentation surgery with limited side effects together with intraoperative opioid-sparing effect.
\end{abstract}

Keywords: $\alpha_{2}$-Agonist, Controlled hypotension, Dexmedetomidine infusion, Loading dose, Maintenance dose, Spine surgery.

\begin{tabular}{|l|c|c|c|}
\hline Article History & Received: May 30, 2019 & Revised: July 19, 2019 & Accepted: August 4, 2019 \\
\hline
\end{tabular}

\section{INTRODUCTION}

Perioperative hemodynamic stability is the cornerstone step during spine surgery. During surgery, low arterial pressure predisposes patients to spinal cord ischemia, on the other hand, a sudden rise in arterial pressure can cause bleeding in the surgical field and render surgical difficulties. Maintaining a clear surgical field helps surgeons to reduce surgery time, which in turn reduces the total blood loss and improving postoperative surgical outcome. Various anesthetics and vaso-

\footnotetext{
Address correspondence to this author at Department of Anesthesia and Intensive Care, Faculty of Medicine, Ain Shams University, Cairo, Egypt; Tel: 002/01222530020; E-mail: rahamhasan@yahoo.com
}

active agents have been used to provide controlled hypotension: volatile anesthetics, vasodilators, $\beta$-adrenergic blockers, Ca-channel blockers, $\alpha_{2}$-agonists, and magnesium sulphate. Drugs used in hypotensive anesthesia had to be easily administered, with the short onset of time, quick offset on discontinuation with negligible adverse effects [1].

Dexmedetomidine in its known dose range of 0.2 to 0.7 $\mu \mathrm{g} / \mathrm{kg} /$ hour has a rapid onset, with a half-life of distribution of around 6 minutes and elimination half-life of 2 hours [2]. It elicits a biphasic blood pressure response: A short hypertensive phase followed by hypotension. The 2 phases are supposed to be mediated by 2 different $\alpha_{2}$-AR subtypes: the $\alpha_{2} \mathrm{~B}-\mathrm{AR}$ is responsible for the initial hypertensive phase, whereas 
hypotension is mediated by the $\alpha_{2} \mathrm{~A}-\mathrm{AR}$. Rapid dexmedetomidine infusion with a Loading Dose (LD) of $1 \mu \mathrm{g} / \mathrm{kg} /$ hour (especially if given in short time, $<10$ minutes) may cause a transient increase in blood pressure mediated by both: peripheral $\alpha_{2} \mathrm{~B}-\mathrm{AR}$ vasoconstriction and the activation of peripheral $\alpha_{1}$ post-junctional adrenergic receptors [3]. Dexmedetomidine loses the selectivity of $\alpha_{2}$ receptors as dosage increases through IV bolus injection or rapid infusion (This rise in blood pressure can be attenuated by a slow infusion and by avoiding bolus administration of the drug). But decreased blood pressure and heart rate, are observed with ongoing therapy within 15 minutes, mediated by central $\alpha_{2} \mathrm{~A}-\mathrm{AR}$, that decreases the release of noradrenaline from the sympathetic nervous system [4].

We designed this randomized, double-blind study to evaluate the effectiveness of the administration of Dexmedetomidine infusion at a dose of $0.5 \mu \mathrm{g} / \mathrm{kg} / \mathrm{h}$ without a loading dose during lumbar fixation procedures under GA. We compared intraoperative hemodynamics in both the groups, intraoperative analgesic consumption, intraoperative blood loss, postoperative sedation scores, intraoperative need for rescue hypotensive agents, and finally the satisfaction of both the surgeons and patients.

To our knowledge, the present study is the first to evaluate the effect of Dexmedetomidine infusion without loading dose as an efficient hypotensive agent during spinal fixation procedures.

\section{METHODS}

After obtaining approval from the Ain Shams University local ethics committee and written informed consent from all the patients, 60 patients were enrolled in our study. This prospective, randomized double-blinded controlled study was conducted in accordance with the current Declaration of Helsinki at Ain Shams University Hospital between October 2018 and February 2019.

\subsection{Study Population}

60 patients, of both the genders, who were scheduled for elective lumbar spine instrumentation ( 2 or more spinal levels) surgery, with an age range of 18 to 65 years, body weight range of 70 to $80 \mathrm{~kg}$ and physical status American Society of Anesthesiologist (ASA) I\&II, participated in this study.

Exclusion criteria were: Patients who had respiratory or cardiac dysfunction, renal insufficiency, liver impairment, or bleeding disorders were excluded from the study.

\subsection{Patients' Recruitment and Randomization}

The patients were randomized into 2 groups: Group C (Control group) and Group D (Dexmedetomidine group). Randomization was performed using computer-generated random number tables in opaque sealed envelopes that were prepared by an anesthesiologist who was not part of the study. On the scheduled time of operation, the head nurse opened each envelope just before the surgery, prepared the infusion solution and handled it to the anesthesiologist who was blinded to the solution. He then determined collected perioperative data.
Group D: Patients received $0.5 \mu \mathrm{g} / \mathrm{kg} / \mathrm{h}$ of Dexmedetomidine.

Dexmedetomidine dosage was diluted in $50 \mathrm{ml}$ syringe of normal saline.

Group C: Patients received equal volume and rate of normal saline as Group D.

This dosing regimen is in accordance with the existing guidelines [5].

\subsection{Anesthetic Technique}

Preoperative evaluation for both the groups included a detailed history, physical examination and full laboratory investigations. On arrival to the operating room, standard continuous monitoring was applied (5 leads electrocardiogram, non invasive blood pressure monitoring, pulse oximetry) and 18 gauge IV cannula was inserted and $6-8 \mathrm{~mL} / \mathrm{kg} / \mathrm{h}$ crystalloid solution was started as a preload before prone positioning. Preoperative medications as midazolam $2 \mathrm{mg}$, ranitidine $50 \mathrm{mg}$ and metoclopramide $10 \mathrm{mg}$ were all given intravenously with each medication diluted in $10 \mathrm{~mL}$ normal saline.

General Anesthesia (GA) induction and maintenance were achieved by means of standard agents after pre-oxygenation with $100 \%$ oxygen for three minutes. Propofol was first administered at a dose of $2 \mathrm{mg} / \mathrm{kg}$ followed by $10 \mathrm{mg}$ morphine sulphate IV and endotracheal intubation was facilitated with atracurium $0.5 \mathrm{mg} / \mathrm{kg}$ as a neuromuscular blocker. After tracheal intubation, another large bore IV cannula was inserted for warm fluids and blood transfusion. The patient was then positioned prone, ensuring that the eyes, nose, breast, genitalia and abdomen were all free of pressure and there was no undue compression to the vessels or hindrance to respiration.

With skin incision, a bolus of $100 \mu \mathrm{g}$ fentanyl was given intravenously and the blinded solution was started with the predetermined rate. All the patients involved were mechanically ventilated with a tidal volume of $6-8 \mathrm{~mL} / \mathrm{kg}$, respiration rate at 12-16 breath per minute. End-tidal $\mathrm{CO}_{2}$ was kept between 35-40 $\mathrm{mmHg}$. Anesthesia was maintained with isoflurane 1-2 MAC and atracurium $10 \mathrm{mg}$ was given every 20 minutes.

For hypotensive anesthesia, we tried to achieve the target MAP of 65-70 mmHg. Mean Arterial Pressure (MAP) = [systolic blood pressure $+(2 \mathrm{x}$ diastolic blood pressure $)] / 3$. Intraoperatively, if the blinded infused solution did not achieve the target MAP, we gave the following medications through scheduled steps: fentanyl boluses with a maximum dose of 200 $\mu \mathrm{g}$ all over surgery (100 $\mu \mathrm{g}$ fentanyl given at skin incision was not included). If there was no response and target Mean Blood Pressure (MBP) was not achieved, propofol infusion was started at a start rate of $6 \mathrm{mg} / \mathrm{kg} / \mathrm{h}$ [6]. If the MAP could not be maintained at the desired level with all the previous approaches, a final step was nitroglycerin infusion at a rate of $1-5 \mu \mathrm{g} / \mathrm{kg} / \mathrm{min}$ [1] which if failed, the patient would be excluded.

Any event of severe hypotension ( $\mathrm{MBP}<60 \mathrm{mmHg}$ ) was treated with: A fluid bolus of $500 \mathrm{~mL}$ IV crystalloid, decreasing isoflurane concentration to $0.6 \%$ and the blinded 
infused solution would be stopped temporarily. If no response within 5 minutes; 6 mg ephedrine would be given IV and was repeated if required.

Bradycardia was treated with: $0.6 \mathrm{mg}$ IV atropine bolus and repeated as required in addition to stopping the blinded infused solution. Bradycardia was defined as the Heart Rate (HR) $<50$ beats/min accompanied with hemodynamic instability or an HR $<40$ beats/ min with or without hemodynamic instability while tachycardia is defined as a $20 \%$ increase from baseline in HR.

Intraoperative blood loss for each patient was calculated by assessing the surgical gauze pads and the suction bottle. If blood loss was above the allowable limit, it was replaced accordingly.

As a way to minimize intraoperative blood loss, a loading dose of Tranexamic Acid $10 \mathrm{mg} / \mathrm{kg}$ was administered to all patients in both the groups over a period of 30 minutes before skin incision. Continuous infusion at a rate of $1 \mathrm{mg} / \mathrm{kg} / \mathrm{h}$ was administered after skin incision till the end of the surgical procedure. This dosing regimen followed current literature and guidelines [7].

After turning the patient supine, the inhalational agent was turned off, residual neuromuscular blockade was reversed with neostigmine $(50 \mu \mathrm{g} / \mathrm{kg})$ and atropine $(0.01 \quad \mathrm{~m} / \mathrm{kg})$ and extubation was done.

Patients were observed in the Postoperative Care Unit (PACU) for 2 hours. The time of arrival there was defined as 0 $\mathrm{h}$ postoperatively. The postoperative analgesic plan was: Fixeddose of paracetamol 1 gram/6 hours (IV) plus $30 \mathrm{mg}$ ketolorac/8 hours IV infusion. The patients started their $1^{\text {st }}$ dose of both the drugs in PACU.

\subsection{Outcome Measures}

Our primary outcome was to detect the effectiveness of dexmedetomidine infusion without a bolus dose in achieving MAP $65-70 \mathrm{mmHg}$ intraoperatively without the need of rescue hypotensive agents. Secondary outcomes were: Recovery time, intraoperative analgesic consumption, patient and surgeon satisfaction and finally intraoperative blood loss.

(1) Demographic data and patients' characteristics.

(2) Mean blood pressure, and heart rate were measured preoperatively then after intubation then at $5^{\text {th }}, 10^{\text {th }}, 15^{\text {th }}, 30^{\text {th }}$, $45^{\text {th }}, 60^{\text {th }}, 90^{\text {th }}, 120^{\text {th }}, 150^{\text {th }}$, and $180^{\text {th }}$ min after prone positioning and finally after extubation. Postoperatively, mean blood pressure, and heart rate were recorded every hour for 2 hours in PACU.

(3) Both the groups were compared with reference to intraoperative blood loss and blood transfusion requirement.

(4) The number of patients who required: Propofol infusion, and nitroglycerin infusion was recorded.

(5) The number of patients who stopped Dexmedetomidine infusion was recorded.

(6) Recovery time (time interval between the stopping of isoflurane and extubation) was noted.

(7) The duration of surgery in minutes (time from skin incision till the end of skin closure).

(8) Total intraoperative fentanyl consumption in microgram (The bolus dose given at skin incision was not included).

(9) Assessment of postoperative sedation level using "University of Michigan Sedation Scale (UMSS)" [8].

The UMSS is a simple observational tool that assesses the level of alertness on a five-point scale ranging from 1 (wide awake) to 5 (unarousable with deep stimulation) (Table 1).

It will be assessed every hour for 2 hours on admission to PACU.

\subsection{Statistical Analysis}

Using PASS 13 for sample size calculation and based on data of the study by Jamaliya and her colleagues [9], sample sizes of 29 per group achieved $80 \%$ power to detect a difference of $15 \mathrm{mmHg}$ in decrease in MABP between the 2 groups and with a significance level (alpha) of 0.05 using a two-sided two-sample t-test. Thirty patients per group were included to replace missing data.

The statistical analysis was performed using a standard SPSS software package version 21 (Chicago, IL). Normally distributed numerical data are presented as mean \pm SD and differences between groups were compared using the independent Student's t-test, while, data, not normally distributed were compared using Mann-Whitney test and are presented as median (IQR). Moreover, categorical variables were analyzed using the $\chi^{2}$ test or Fisher exact test and are presented as a number. All $\mathrm{P}$ values are two-sided. $P<0.05$ is considered statistically significant.

Table 1. University of Michigan Sedation Scale (UMSS) [8].

\begin{tabular}{|c|l|}
\hline Score & \multicolumn{1}{|c|}{ Patient state } \\
\hline 0 & Awake/alert \\
\hline 1 & Minimally sedated: Tired/sleepy, appropriate response to verbal conversation and/or sounds \\
\hline 2 & Moderately sedated: Somnolent/sleeping, easily aroused with light tactile stimulation \\
\hline 3 & Deeply sedated: Deep sleep, arousable only with significant physical stimulation \\
\hline 4 & Unarousable \\
\hline
\end{tabular}


Table 2. Baseline demographics.

\begin{tabular}{|c|c|c|c|}
\hline Demographics & Group C $(\mathbf{n}=\mathbf{3 0})$ & Group D $(\mathbf{n}=\mathbf{3 0})$ & $\boldsymbol{P}$-value \\
\hline Age in years & $47.28 \pm 12.45$ & $49.2 \pm 13$ & 0.857 \\
\hline Sex & $16 / 14$ & $15 / 15$ & 1 \\
\hline ASA(I/II) & $14 / 16$ & $15 / 15$ & 1 \\
\hline BW in Kg & $75.3 \pm 9.4$ & $74.4 \pm 6.8$ & 0.92 \\
\hline BMI & $27.34 \pm 2.05$ & $27 \pm 2.113$ & 0.97 \\
\hline
\end{tabular}

Data are presented as mean $\pm \mathrm{SD}$, or ratio

$P$-value $<0.05$ is considered statistically significant

Table 3. Intraoperative Data.

\begin{tabular}{|c|c|c|c|}
\hline Intraoperative Data & Group C $(n=30)$ & Group D $(n=30)$ & $P$-value \\
\hline Duration of surgery(minute) & $199.3 \pm 18.65$ & $200.6 \pm 20.66$ & 0.97 \\
\hline Recovery time(minute) & $2.07 \pm 0.84$ & $5.1 \pm 1.55$ & $0.001^{*}$ \\
\hline Blood loss (mL) & $620 \pm 129.1$ & $610 \pm 150.6$ & 0.774 \\
\hline \multicolumn{3}{|c|}{ Number of patients who received intraoperative blood transfusion } & \multirow{4}{*}{0.98} \\
\hline - 0 units given & 15 & 16 & \\
\hline - 1 unit given & 12 & 11 & \\
\hline-2 units given & 3 & 3 & \\
\hline
\end{tabular}

Data are presented as mean $\pm \mathrm{SD}$, or ratio

$P$-value $<0.05$ is considered statistically significant

\section{RESULTS}

All the patients completed the entire study and their data were included in the final analysis. The two groups were similar as regards: age, sex, weight, BMI and ASA physical status (Table 2). The 2 groups were also similar with respect to the duration of the surgical operation $(199.3 \pm 18.65 \mathrm{~min}$ versus $200.6 \pm 20.66)$, intraoperative blood loss $(620 \pm 129.1$ $\mathrm{mL}$ versus $610 \pm 150.6 \mathrm{~mL}$ ), number of patients who received blood intraoperatively ( 15 out of 30 versus 14 out of 30 ); all in control group versus dexmedetomidine group, respectively (Table 3).

All the patients in the dexmedetomidine group achieved and maintained the target MAP during the period of observation without the need for rescue therapy except 2 out of 30 patients who needed propofol rescue therapy. On the contrary, in the control group, all the patients required rescue therapy (both propofol and NG) (Fig. 1 and Table 4).

In the current study, episodes of hypotension between control and dexmedetomidine groups were comparable. In control group: 2 patients had episodes of severe hypotension with MBP $<60 \mathrm{mmHg}$ that was managed by decreasing NG infusion rate whereas in dexmedetomidine group: 3 patients had severe hypotension with $\mathrm{MBP}<60 \mathrm{mmHg}$, of which, one patient responded by fluids and the other 2 patients required to stop dexmedetomidine infusion.

It was also observed that HR in the dexmedetomidine group was significantly lower compared to the control group at all time points during period of observation starting from the $15^{\text {th }}$ minute after positioning till the end of surgery. No severe bradycardia episodes occurred in any patient in both the groups (Fig. 2).

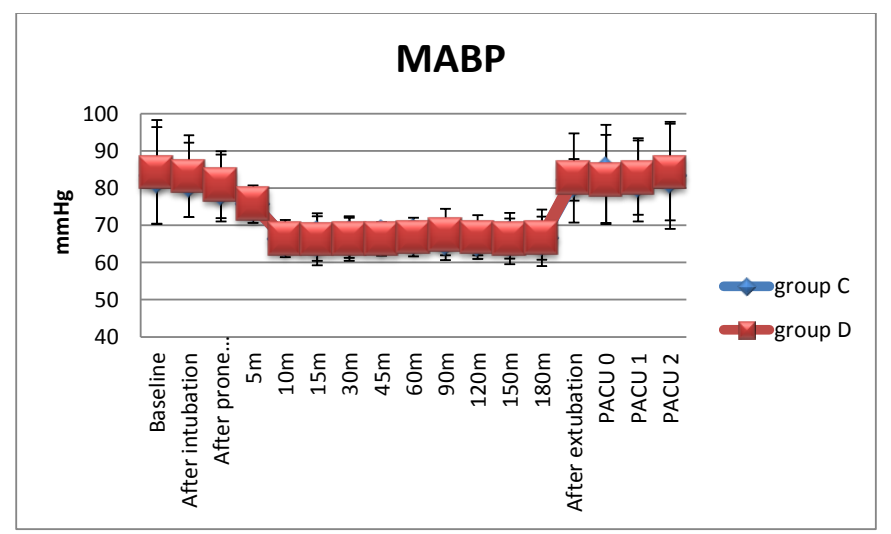

Fig. (1). Comparison of MBP between 2 groups.

Lines are mean values and error bars are $\mathrm{SD}$

$\mathrm{MBP}=$ Mean Blood Pressure, Group $\mathrm{C}=$ Control Group, Group $\mathrm{D}=$ Dexmedetomidine Group. 


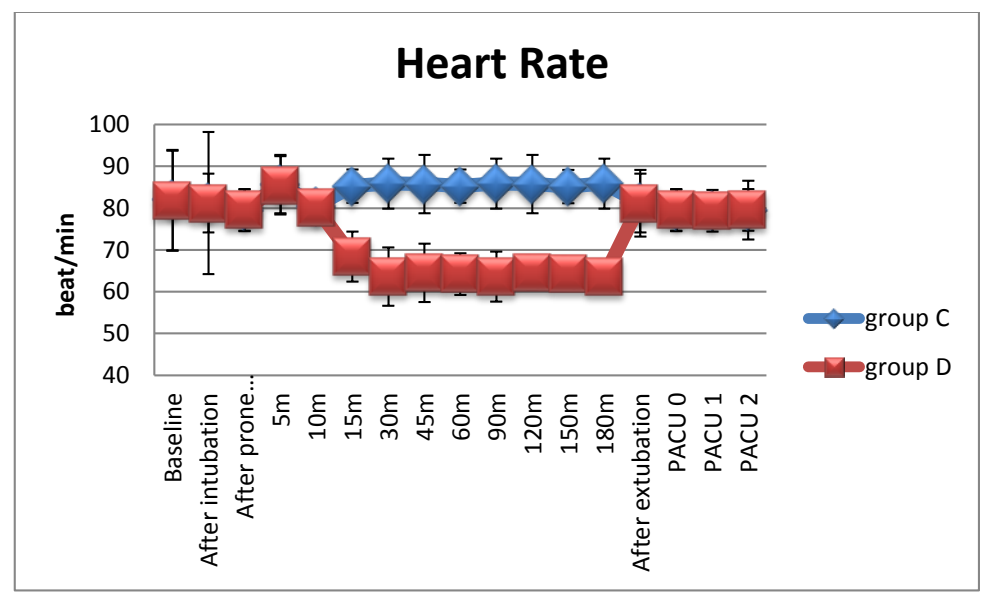

Fig. (2). Comparison of HR between 2 groups.

Lines are mean values and error bars are SD

$\mathrm{HR}=$ Heart Rate, Group $\mathrm{C}=$ Control Group, Group $\mathrm{D}=$ Dexmedetomidine Group.

Table 4. Number of patients needed rescue therapy and amount of intraoperative analgesic consumption among the 2 groups.

\begin{tabular}{|c|c|c|}
\hline Intraoperative Analgesic & Group C (n=30) & Group D (n=30) \\
\hline Propofol & 30 & 2 \\
\hline Nitroglycerine & 30 & $<0.001^{*}$ \\
\hline Intraoperative fentanyl $(\boldsymbol{\mu g})$ & $169.64 \pm 34.26$ & $<0.001^{*}$ \\
\hline
\end{tabular}

Data are presented as mean $\pm \mathrm{SD}$, or number of patients

$P$-value $<0.05$ is considered statistically significant

Table 5. Sedation scores among 2 groups.

\begin{tabular}{|c|c|c|c|}
\hline Sedation Scores & Group C $(\mathbf{n}=\mathbf{3 0})$ & Group D $(\mathbf{n}=\mathbf{3 0})$ & $2(1-2)$ \\
\hline $\mathbf{0}$ & $1(0-1)$ & $0(0-0)$ & $<0.001^{*}$ \\
\hline $\mathbf{1}$ & $0(0-0)$ & $0(0-0)$ & 0.083 \\
\hline
\end{tabular}

Data are presented as median (IQR)

$P$-value $<0.05$ is considered statistically significant.

There was a significant reduction in intraoperative fentanyl consumption in dexmedetomidine group compared to those of the control group. Total fentanyl consumption in the control group was $169.64 \pm 34.26 \mu \mathrm{g}$ versus $75 \pm 25.43 \mu \mathrm{g}$ in the dexmedetomidine group $(P$-value $=<0.001)$ (Table 4$)$.

Regarding recovery time, it was significantly longer in the dexmedetomidine group than in the control group $5.1 \pm 1.55$ versus $2.07 \pm 0.84$ respectively (Table 3 ). Also, patients in the dexmedetomidine group showed higher sedation scores in the $1^{\text {st }}$ postoperative hour in PACU when compared to the control group (Table 5).

\section{DISCUSSION}

In most circumstances, the hemodynamic effects of dexmedetomidine including bradycardia and hypotension are considered adverse consequences. However, in surgeries necessitating controlled hypotension, the lowering of MAP may be the desired effect [10]. The major observation in our study was that dexmedetomidine without a loading dose was successfully used to achieve induced hypotension and only 2 patients out of 30 required rescue therapy. Also, dexme- detomidine maintained heart rate than in the control group from the $15^{\text {th }}$ minute after positioning till the end of surgery. Also, lower intraoperative fentanyl consumption was observed in the dexmedetomidine group.

The demographic data of the patients were comparable. The duration of surgery, intraoperative blood loss, and intraoperative blood transfusions were also comparable between the 2 groups; although it was expected to experience more blood loss in the control group that used NG as occurred in previous studies $[1,9]$. Both the groups achieved MBP 65-70 $\mathrm{mmHg}$ all over the examined times but with different intraoperative interventions. In dexmedetomidine group, this was achieved by continuous infusion of dexmedetomidine 0.5 $\mu \mathrm{g} / \mathrm{kg} / \mathrm{h}$, in addition to fentanyl increments with a mean of $75 \pm$ $25.43 \mu \mathrm{g}$ with almost no rescue therapy at all, except in 2 patients who needed propofol infusion. On the other hand in the control group, propofol infusion with rate $6 \mathrm{~mL} / \mathrm{hour}$, and nitroglycerin infusion in a dose range of $1-5 \mu \mathrm{g} / \mathrm{kg} / \mathrm{min}$ were needed in all the patients in order to achieve our target MBP. Added to this, fentanyl increments with mean of $169.64 \pm$ $34.26 \mu \mathrm{g}$ were used in the control group. In a study done by 
Ngwenyama and his colleagues [5], they used dexmedetomidine $0.5 \mu \mathrm{g} / \mathrm{kg} / \mathrm{h}$ without a Loading Dose (LD) after induction of anesthesia in patients undergoing Posterior Spinal Fixation (PSF) for either idiopathic or neuromuscular scoliosis. Ngwenyama noticed hemodynamic stability with decreased propofol infusion rate in the dexmedetomidine group when compared to the control group. Other studies also highlighted the same effect of dexmedetomidine but with a preceding LD whether given before positioning at a dose of $1 \mu \mathrm{g} / \mathrm{kg} / \mathrm{h} \mathrm{[1,9}$, $11-14]$ or after positioning with a loading dose of $0.5 \mu \mathrm{g} / \mathrm{kg} / \mathrm{h}$ $[15,16]$. In all of these studies, dexmede- tomidine proved its high-efficiency and success in achieving intraoperative targeted induced hypotension and intraoperative hemodynamic stability.

Regarding intraoperative HR, patients in the dexmedetomidine group had a significantly lower HR than the control group starting from the $15^{\text {th }}$ min after positioning till the end of surgery and that was statistically significant indicating greater hemodynamic stability. This 15 minutes of delay is attributed to the delayed onset of dexmedetomidine since it was not proceeded by LD. The beneficial bradycardic effect of dexmedetomidine was also noticed in spine surgeries whether dexmedetomidine was compared to: placebo [5], NG [1,9], Nitroprusside [14], clonidine [11, 12], esmolol [13, 16], or ketamine [15]. In the current study, episodes of hypotension and bradycardia between control and dexmedetomidine groups were comparable.

In the present study, dexmedetomidine group experienced longer recovery time than in the control group and that is due to its prolonged effect as it has a high affinity for its receptors. This goes with the results of Ibrahim \& his colleagues [16] who reported significantly longer recovery time in dexmedetomidine group $(27.2 \pm 13.4$ minutes $)$ when compared to control and esmolol groups $(17.0 \pm 9.4 \mathrm{~min}, 19.1 \pm 11.7 \mathrm{~min}$, respectively). The recovery time in this study with dexmedetomidine was shorter $5.1 \pm 1.55$ minute when compared to Ibrahim's study, and this may be attributed to the loading dose given in Ibrahim's study and their larger maintenance dose of dexmedetomidine intraoperatively $(0.4-0.7 \mu \mathrm{g} / \mathrm{kg} / \mathrm{h})$.

Regarding postoperative sedation assessed by UMSS, the sedation score was more in the dexmedetomidine group compared to the control group during $1^{\text {st }}$ hour in PACU, after which all the patients in both the groups were fully conscious. This was in agreement with the results of Vali \& his colleagues [1] who reported more sedation in dexmedetomidine group when compared to NG, but his sedation was short lived; from $5^{\text {th }}$ min to $20^{\text {th }}$ min in PACU using Ramsay Sedation Assessment Scale. This can be attributed to the discontinuation of dexmedetomidine infusion earlier in their study.

The current study also showed that the total intraoperative fentanyl consumption was significantly lower in the dexmedetomidine group $(75 \pm 25.43 \mu \mathrm{g})$ when compared to the control group $(169.64 \pm 34.26 \mu \mathrm{g})$. This can be due to the analgesic effect of dexmedetomidine. Dexmedetomidine's analgesic effect with reduced total intraoperative fentanyl amount was similar to those of the previous studies. In a study done by Nazir \& his colleagues [13], total fentanyl dose in Esmolol group was $180.8 \pm 18.7 \mu \mathrm{g}$ and $100.8 \pm 8.9 \mu \mathrm{g}$ in the dexmedetomidine group. Also, in Ibrahim's study [16], mean intraoperative total fentanyl in the control and esmolol group was significantly higher than in the dexmedetomidine group $(511 \pm 90.43 \mu \mathrm{g}, 441.5 \pm 65.79 \mu \mathrm{g} \& 384.5 \pm 50.62 \mu \mathrm{g})$ fentanyl, respectively.

\section{CONCLUSION}

From the results of the present study, we conclude that dexmedetomidine without a loading dose could be efficaciously and safely used to attain a target level of MAP with the desired hemodynamic stability in posterior fixation surgeries without significant adverse effects in the intraoperative or early postoperative period.

\section{ETHICS APPROVAL AND CONSENT TO PARTI- CIPATE}

The research was carried out after obtaining approval from the Ain Shams University Local Ethics Committee.

\section{HUMAN AND ANIMAL RIGHTS}

No animals were used in this research. All human research procedures followed were in accordance with the ethical standards of the committee responsible for human experimentation (institutional and national), and with the Helsinki Declaration of 1975, as revised in 2013.

\section{CONSENT FOR PUBLICATION}

Written informed consent was obtained from all the patients.

\section{AVAILABILITY OF DATA AND MATERIAL}

The authors confirm that the data supporting the findings of this research are available within the article.

\section{FUNDING}

None.

\section{CONFLICTS OF INTEREST}

The authors declare no conflict of interest, financial or otherwise.

\section{ACKNOWLEDGEMENTS}

Declared none.

\section{REFERENCES}

[1] Vali L, Dwivedi R, Vali A. Clinical evaluation of efficacy of dexmedetomidine in maintaining intraoperative haemodynamics in posterior fixation surgery following traumatic spine injury. Int J Biol Adv Res 2017; 8(4): 157-62.

[2] Kaur M, Singh PM. Current role of dexmedetomidine in clinical anesthesia and intensive care. Anesth Essays Res 2011; 5(2): 128-33. [http://dx.doi.org/10.4103/0259-1162.94750] [PMID: 25885374]

[3] Fairbanks CA, Stone LS, Wilcox GL. Pharmacological profiles of alpha 2 adrenergic receptor agonists identified using genetically altered mice and isobolographic analysis. Pharmacol Ther 2009; 123(2): 224-38. [PMC free article]. [PubMed]. [Google Scholar]. [http://dx.doi.org/10.1016/j.pharmthera.2009.04.001] [PMID: 1939 3691]

[4] Afsani N. Clinical application of dexmedetomidine. S Afr J Anaesthesiol Analg 2010; 16: 50-6. [Google Scholar].

[5] Ngwenyama NE, Anderson J, Hoernschemeyer DG, Tobias JD. Effects of dexmedetomidine on propofol and remifentanil infusion 
rates during total intravenous anesthesia for spine surgery in adolescents. Paediatr Anaesth 2008; 18(12): 1190-5.

[http://dx.doi.org/10.1111/j.1460-9592.2008.02787.x] [PMID: 1907 6573]

[6] Ismail EA, Bakri MH. Evaluation of propofol dose based on total body weight in obese compared to non-obese patients guided by bispectral index. Age (Omaha) 35(11): 37-10. [years].

[7] Saleh AN, Mostafa RH. Increased nociception following administration of different doses of tranexamic acid in adolescent idiopathic scoliosis surgery. Open Anesth J 2018 Sep 28; 12(1) [http://dx.doi.org/10.2174/2589645801812010061]

[8] Malviya S, Voepel-Lewis T, Tait AR, Merkel S, Tremper K, Naughton N. Depth of sedation in children undergoing computed tomography: Validity and reliability of the University of Michigan Sedation Scale (UMSS). Br J Anaesth 2002; 88(2): 241-5.

[http://dx.doi.org/10.1093/bja/88.2.241] [PMID: 11878656]

[9] Jamaliya RH, Chinnachamy R, Maliwad J, Deshmukh VP, Shah BJ, Chadha IA. The efficacy and hemodynamic response to Dexmedetomidine as a hypotensive agent in posterior fixation surgery following traumatic spine injury. J Anaesthesiol Clin Pharmacol 2014; 30(2): 203-7.

[http://dx.doi.org/10.4103/0970-9185.130021] [PMID: 24803758

[10] Tobias JD, Berkenbosch JW. Initial experience with dexmedetomidine in paediatric-aged patients. Paediatr Anaesth 2002; 12(2): 171-5. [http://dx.doi.org/10.1046/j.1460-9592.2002.00805.x] [PMID: 1188 2231]

[11] Mariappan R, Ashokkumar H, Kuppuswamy B. Comparing the effects of oral clonidine premedication with intraoperative dexmedetomidine infusion on anesthetic requirement and recovery from anesthesia in patients undergoing major spine surgery. J Neurosurg Anesthesiol 2014; 26(3): 192-7.

[http://dx.doi.org/10.1097/ANA.0b013e3182a2166f] [PMID: 2388 7684]

[12] Suyasa IK, Ryalino C, Pradnyani NP. Dexmedetomidine provides better hemodynamic stability compared to clonidine in spine surgery 2018; 2(3): 90-4.

[http://dx.doi.org/10.15562/bjoa.v2i3.100]

[13] Nazir O, Wani MA, Ali N, et al. Use of dexmedetomidine and esmolol for hypotension in lumbar spine surgery. Trauma Mon 2016; 21(3)e22078

[http://dx.doi.org/10.5812/traumamon.22078] [PMID: 27921016]

[14] El-Gohary MM, Arafa AS. Dexmedetomidine as a hypotensive agent: Efficacy and hemodynamic response during spinal surgery for idiopathic scoliosis in adolescents. Egypt J Anaesth 2010; 26(4): 305-11.

[http://dx.doi.org/10.1016/j.egja.2010.07.001]

[15] Mitra R, Prabhakar H, Rath GP, Bithal PK, Khandelwal A. A comparative study between intraoperativelow-dose ketamine and dexmedetomidine, as an anaesthetic adjuvant in lumbar spine instrumentation surgery for the post-operative analgesic requirement. J Neuroanaesthesiology Crit Care 2017 Aug; 4(02)091 [http://dx.doi.org/10.4103/jnacc-jnacc-3.17]

[16] Ibraheim OA, Abdulmonem A, Baaj J, Zahrani TA, Arlet V. Esmolol versus dexmedetomidine in scoliosis surgery: Study on intraoperative blood loss and hemodynamic changes. Middle East J Anaesthesiol 2013; 22(1): 27-33.

[PMID: 23833847]

(C) 2019 Moharram et al.

This is an open access article distributed under the terms of the Creative Commons Attribution 4.0 International Public License (CC-BY 4.0), a copy of which is available at: (https://creativecommons.org/licenses/by/4.0/legalcode). This license permits unrestricted use, distribution, and reproduction in any medium, provided the original author and source are credited. 